\title{
WHY EXTENDING ACTIONS THROUGH TIME CAN VIOLATE A MORAL RIGHT TO PRIVACY
}

\author{
Björn Lundgren
}

1

ECENTLY, Ingmar Persson and Julian Savulescu-in the context of defending their book Unfit for the Future and the irrelevance of a moral right to ing an action in time could "bring a moral right into existence." In this brief reply, I will argue that the right to privacy can be violated by temporally extending actions that in themselves do not violate the right to privacy.

Persson and Savulescu "take a moral right to privacy to be a right against others that they don't acquire (and sustain) certain (true) beliefs about us” (35). Furthermore, according to them, a moral right to privacy does not protect against stalking or gawking. ${ }^{2}$ This is because, first, they deny any moral right "not [to] be tailed and/or stared at for a short period of time" (36). Second, they argue that if an action $A$ does not violate a right $R$ then a temporal extension of $A$ does not violate $R$ either, reasoning that "it would be odd if such a right eventually kicks in if this period is gradually extended: How could the mere passage of time bring a moral right into existence?" (36). Hence, if we accept their argument, a moral right to privacy does not protect against stalking or gawking because it does not protect against being briefly tailed/followed or stared/looked at.

Moreover, in defending the idea that a moral right to privacy does not protect against stalking or gawking, Persson and Savulescu attempt to explain why many legal systems may reasonably uphold "a legal right not to be systematically followed around." They argue that this legal right cannot be "justified by a moral right to the same effect" because we do not "have a moral right not to be tailed and/or stared at for a short period of time"; instead they think that legal protection against stalking or gawking is better defended because it is "highly unlikely that someone takes the trouble of keeping an eye on somebody else for [a]

1 Persson and Savulescu, "The Irrelevance of a Moral Right to Privacy for Biomedical Moral Enhancement," 36, hereafter cited parenthetically.

2 By "stalking" (and "gawking," respectively), I will henceforth mean tailing or following (staring or looking at) a person for an extended period of time. 
lengthy period of time, unless he plans to use this information for some purpose" (i.e., to violate someone's right). Furthermore, they hold that it is this risk that makes people uneasy about being stalked (36).

This raises at least three questions, which I will address in the following sections. First, is it correct-on their own definition of a moral right to privacy-to say that stalking and gawking do not violate a moral right to privacy? I will argue that it is not. Moreover, I will show that the same holds true for other conceptions of a moral right to privacy to illustrate a broader conceptual agreement that a moral right to privacy can be violated by stalking and gawking. Second, is there any other reason (i.e., other than fear of sinister actions) why people might be uneasy about being stalked or gawked at? I will argue that there is and that these reasons explain why a right to privacy should protect against stalking and gawking. Third, do we more broadly have reasons to think that a moral right to privacy should protect against stalking and gawking? I will argue that we do, because such actions are not part of what we implicitly consent to by entering a public sphere.

As previously noted, Persson and Savulescu argue that a moral right to privacy does not protect against stalking or gawking because (1) it does not protect against being followed or being looked at briefly and (2) it does not protect against temporal extensions of actions that it does not protect against.

However, it is easy to see that Persson and Savulescu's claim is false on their own definition of a moral right to privacy. Remember that according to their definition, a moral right to privacy is a "right against others that they don't acquire (and sustain) certain (true) beliefs about us" (35). Consider the following example: you are walking in public and you see a person who is suddenly, by accident, nude (e.g., because a powerful gust of wind has blown her clothes away). Because the person's nudity is accidental, it is fair to say that by seeing that person nude (only for a moment), you have not violated that person's right to privacy. Yet, suppose that it is obvious to you that this person does not enjoy being publicly nude. If you were then to temporally extend the action of looking at that nude person, would that be a violation of their right to privacy? It is clear that one consequence of extending the action temporally is that over time you would acquire more true beliefs about that person. Hence, on Persson and Savulescu's definition, extending an action in time can violate a moral right to privacy. ${ }^{3}$

3 Strangely, as indicated in previous quotes, Persson and Savulescu seem to recognize that extendedly looking at or following someone implies that one acquires (more) information about that person. An anonymous reviewer pointed out that because they use the concept 
More generally, the same type of argument can arguably be applied to any definition of a moral right to privacy that includes a moral right against others' access or control of informational privacy. For example, according to Adam D. Moore, a right to privacy "is a right to limit public access to oneself and to information about oneself." While applying Moore's conception of a right to privacy would require a closer analysis, it arguably follows that we have a right to restrict others' access to information about us (i.e., we have a right that restricts people from, e.g., gawking at our nude bodies), and hence that unwanted stalking or gawking can violate such a right. Furthermore, according to Helen Nissenbaum's account of privacy as contextual integrity, the right to privacy "is a right to live in a world in which our expectations about the flow of personal information are, for the most part, met." On Nissenbaum's account, it arguably follows that gawking and stalking would constitute a violation of our right to privacy because they violate our normal expectations of personal information flow (i.e., gawking and stalking are outside of the appropriate contextual norms, because, e.g., gawking at someone's nude body in the previously given example would violate some such norm) ${ }^{6}$ Thus, it seems that on Persson and Savulescu's, Moore's, and Nissenbaum's

certain information rather than merely information in their definition, we should perhaps think that it indicates a special kind of information. However, it is clear that what they have in mind is private information (36).

Instead, Persson and Savulescu seem to rest their argument on the idea that information acquisition does not constitute an action and, hence, that information acquisition is permissible because it is not "under the control of our will" (36). However, while we can think of examples in which that analysis might make sense (their best example is of an omniscient being, which cannot help knowing things about us), what matters here is that their analysis fails for the example considered above.

Lastly, another possible interpretation is that they think of information that we can be certain of, but even if that were the case, it would not affect any of my arguments.

4 Moore, "Defining Privacy," 420. The formulation Moore provides should be read as a right to control access. On the following page in his article, he settles for the following formulation: "Definition: A right to privacy is a right to control access to and uses of-places, bodies, and personal information" (421). I am using the above formulation since it allows me to illustrate the plausibility that both control and limited-access conceptions of the right to privacy standardly should result in a similar analysis of the given example.

5 Nissenbaum, Privacy in Context, 231.

6 An anonymous reviewer argued that because Nissenbaum's theory is contextual, my argument above may not hold in some contexts, saying that "in the us, there is a strong (often discussed) sense of 'no reasonable expectation of privacy in public."' Yet, it is clear that Nissenbaum does think that we have some modicum of a right to privacy in public (see Privacy in Context, 116, for examples relating to the United States). This is grounded in her criticism of the private-public distinction and the informational power of social-technical systems. In her discussion on privacy in public (113-26), she concludes that "because of these [socio-technical] powers, there are no actors, no spheres, no information that can be assigned 
accounts of a moral right to privacy, we should hold that such a right protects against gawking and stalking irrespective of whether it protects against briefly looking or following. Moreover, it seems reasonable that this would extend to many other conceptions of the right to privacy as well.

According to Persson and Savulescu, stalking or gawking makes people uneasy because they think that the stalkers or gawkers "are planning to take some actions against" them (36). Yet, this uneasiness can easily be defended on other grounds.

After the \#MeToo movement, it should be clear that extended looking (i.e., gawking) can make a person uneasy even if that person is not worried that the gawker (or a stalker) has sinister plans (although such worries should be taken even more seriously). That is, the extended looking can itself be problematic. One problem is simply that staring at a person can make them feel objectified. ${ }^{7}$

While feeling objectified can be problematic in itself, it can also be problematic for other reasons (i.e., beyond any fear from the gawker/stalker). For example, it has been shown that objectification of women can lead to a form of self-objectification, which in turn can increase negative emotions such as anger and shame. ${ }^{8}$

However, although it is certain that objectification due to gawking can constitute a harm, we can question whether this is the kind of harm that a moral right to privacy should protect against. The answer to this question depends, in part,

unconditionally to the domain of the public, free of all and any constraints imposed by rights of privacy; none are 'up for grabs"' (126).

Moreover, while there may be sensible disagreement about which norms should guide information flows and whether that can be suitably established on Nissenbaum's theory, it is fair to say that there has been an uprising about such norms recently (as I will address in the next section).

7 Note that I write "can" (i.e., temporally extended behavior, such as staring, can constitute a harm). That does not mean that extending such kinds of behaviors is always harmful. For example, in certain settings a person may look at another person, after which that person looks back in a liking manner. This may implicitly indicate a consent to being extendedly looked at (I will discuss the relevance of consent in section III). Therefore, what we may call "romantic staring" may be an example of an action that can be extended over time without being harmful. While there is something interesting to be said about how we qualify the distinction between actions that become harmful if extended and actions that do not, that would be beyond the purpose of this article. My aim here is merely to show that there are some actions that if extended over time would constitute a harm and would violate a moral right to privacy.

8 Koval et al., "How Does It Feel to Be Treated Like an Object?" 894. 
on whether such a harm is a privacy harm. That is, if the harm is a privacy harm, then there is reason to think that a moral right to privacy should protect against such a harm. Consider, again, the previous example about the person that accidentally becomes nude in public (keep in mind that the person obviously does not enjoy being publicly nude). In such a situation, it is fair to say that the nude person is harmed by others' acquisition of personal or privacy-sensitive information about her (here I suppose that information about a person's naked body is a standard example of what can be privacy sensitive). Because this acquisition is a privacy harm, we should hold that a moral right to privacy should protect against it (while we cannot be blamed for purely accidentally seeing someone nude, we can be blamed for extending such a look). ${ }^{9}$

It is important to note that while being exposed in the nude may also be harmful for other reasons (e.g., because the gawker has sinister plans), that does not affect the point that I am making here, since there can be a pure privacy harm without such other factors. ${ }^{10}$ Hence, if we agree that there can be such a harm, then because this harm is rooted in the acquisition of personal or privacy-sensitive information, we should hold that this harm is specifically what a moral right to privacy should protect against. ${ }^{11}$

Although the arguments I have presented should suffice to show how extending an action of looking (or following) can violate a moral right to privacy, in the third and final section, I will address this issue from the perspective of consent and privacy in public.

Consider the example from the previous sections (i.e., you see a person in public accidentally becoming nude). If Persson and Savulescu's argument is correct, you would not violate any right (to privacy or otherwise) of that person by con-

9 Of course, whether an action is a violation of a right to privacy depends on various other conditions. I take it here that the examples I will use either are compatible with or can be adapted to such requirements.

10 See Rachels, "Why Privacy Is Important," for arguments about the nonderivative value of privacy.

11 An anonymous reviewer suggested that the arguments in this section seem to indicate that Persson and Savulescu are wrong to restrict the right to privacy to an information-based account. Although the above issues can be analyzed in terms of a purely information-based account of the right to privacy (i.e., because the harm can always be explained by a process of information transfer), I agree that it would arguably be both easier and more analytically sensible to analyze them in terms of a conception of the right to privacy that also covers, for example, bodily, decisional, or spatial privacy. 
tinuing to look at her (even if she is obviously not comfortable with the current situation). However, as I have argued, this is wrong on the grounds that the nude person is obviously harmed (and that this is a privacy harm), because, for example, we-in accordance with Persson and Savulescu's information-based account of the right to privacy_acquire more (private) information (knowledge) about the individual.

The consequence of accepting an information-based account of the moral right to privacy — such as that of Persson and Savulescu — can be further supported by an argument that it matters whether there is (implicit) consent. This "argument from consent" can also be used to address another related issue: privacy in public. $^{12}$

Whether we have a right to privacy in public is debated, in part, because we allow others to acquire information about us when we enter a public sphere. However, in many situations, these information acquisitions are implicitly consensual and hence unproblematic vis-à-vis a moral right to privacy. That is, by entering a public sphere, you standardly (implicitly) consent to being seen, but - as I have argued - not to being stared at. Why is that? To explain this, let us start by considering that a moral right to privacy protects against being looked at in various situations. For example, when alone in your home, a moral right to privacy morally protects you against a Peeping Tom. Yet, alone in your home you also have a right to look at your surroundings. If both these rights were to apply fully-to everyone-and in public, we would have conflicting rights. People cannot both have a right not to be looked at and a right to look at others.

Some might think that this (supposed) conflict can be resolved because a moral right to privacy does not apply in the public sphere (or that it is limited somehow). While my aim here is not to fully defend the notion of privacy in public, I believe that those that hold that we cannot have privacy in public must defend a notion of privacy as a bivalent concept (e.g., a state, or condition, that you are either in or not). I, however, hold that we can have at least a modicum of privacy in public. That is, if privacy is something that one can have less and more of, then it is reasonable to think that one can have less or more privacy in public (e.g., the person who accidentally becomes nude is in a state of less privacy than she was before). Likewise, it is reasonable to think that one can have a right to privacy in public, a right that provides some protection, in some situations, but perhaps not complete protection in all situations.

My suggestion is, thus, that this prima facie conflict of rights can be resolved, in part, by the fact that by entering the public sphere, we (implicitly) consent to

12 In arguing for this, I do not presume that the concept of (implicit) consent can be used in every situation to determine whether there is a violation of a moral right to privacy. 
being seen. Moreover, by entering the public sphere, we standardly prepare ourselves for the possibility of being seen and take precautions to avoid exposing ourselves too much. For example, most people cover parts of their body to keep others from looking at those parts. Consider, again, the example of the person who accidentally becomes nude in front of us. Granted that she used clothes to partly protect against her body being seen, extended looking at her nude body would not be something that she (implicitly) consented to when entering the public sphere. Similarly, a person that enters the public sphere normally consents to being looked at, but not to being gawked at. There are various illustrative examples that further support this way of analyzing these situations-for example, there are people, such as street performers, who arguably implicitly consent to being extendedly looked at (see note 7 for another illustrative example). Thus, if my arguments are correct, then a moral right to privacy can also be said to morally protect against gawking and stalking because we normally do not (implicitly) consent to such activities. ${ }^{13}$

Some may ask why our moral right to privacy would protect us in this way. That is, why would our moral right to privacy protect against being gawked at in many ordinary public situations? This is where my argument reaches full circle and refers to the previous arguments. The first two arguments that I have presented stand on their own. To some extent, this is true for the argument from consent as well (i.e., we can use this kind of reasoning to make sense of, e.g., why people normally implicitly consent to being looked at in public, but not to being gawked at). However, for full justification of the argument from consent, we must rely on "the argument from harm." This is not circular; instead, it shows a strong coherence between different ways of reasoning about privacy. ${ }^{14}$

To briefly summate: an action @ by an agent $A$ that does not violate a moral right to privacy of an agent $B$ can, if extended temporally, violate $B$ 's moral right

13 Given that people sometimes have a right not to be looked at, it follows that people occasionally have a duty to look away. However, such a duty would arguably be pro tanto (i.e., a duty that can be overridden). The duty can, for example, be overridden in case the person (who has a right not to be extendedly looked at) needs some sort of help and you can only do so by looking at that person, or it may be overridden if you have a need to look in a direction that inadvertently includes extending your gaze at this person (e.g., if you are driving a vehicle and need to look at the road). The precise limits of such a duty are beyond the scope of this paper.

Of course, there are also other arguments that could be used to further extend the support for my position-for example, by reference to respect for persons and what is a private affair (see, e.g., Benn, "Privacy, Freedom, and Respect for Persons"). An anonymous reviewer pointed out that this type of literature may, in particular, be relevant for the discussion in section II. However, because of the desire to keep the discussion short, I could not engage with it in any detail. 
to privacy-for example, because by extending @, $A$ can acquire more information about $B$, something that $B$ has not explicitly or implicitly consented to. Furthermore, $B$ has a right to withhold such a consent, because such actions can harm $B$ relative to her privacy. ${ }^{15}$

Umeå University, Institute for Futures Studies, and Stockholm University bjorn.lundgren@umu.se

\section{REFERENCES}

Benn, Stanly I. "Privacy, Freedom, and Respect for Persons." In Philosophical Dimensions of Privacy: An Anthology, edited by Ferdinand D. Schoeman, 22344. Cambridge: Cambridge University Press, 1984.

Koval, Peter, Elise Holland, Michael J. Zyphur, Michelle Stratemeyer, Jennifer Makovec Knight, Natasha Bailen, Renee J. Thompson, Tomi-Ann Roberts, and Nick Haslam. "How Does It Feel to Be Treated Like an Object? Direct and Indirect Effects of Exposure to Sexual Objectification on Women's Emotions in Daily Life." Journal of Personality and Social Psychology 116, no. 6 (June 2019): 885-98.

Moore, Adam. "Defining Privacy." Journal of Social Philosophy 39, no. 3 (Fall 2008): 411-28.

Nagel, Thomas. "Concealment and Exposure." Philosophy and Public Affairs 27, no. 1 (January 1998): 3-30.

Nissenbaum, Helen. Privacy in Context: Technology, Policy, and the Integrity of Social Life. Stanford, CA: Stanford Law Books, 2010.

Persson, Ingmar, and Julian Savulescu. "The Irrelevance of a Moral Right to Privacy for Biomedical Moral Enhancement.” Neuroethics 12, no. 1 (April 2019): $35-37$.

- Unfit for the Future: The Need for Moral Enhancement. Oxford: Oxford University Press, 2012.

Rachels, James. "Why Privacy Is Important." Philosophy and Public Affairs 4, no. 4 (Summer 1975): 323-33.

15 Many thanks to three anonymous reviewers for the Journal of Ethics and Social Philosophy. Moreover, I want to acknowledge that this work was partially supported by the Wallenberg AI, Autonomous Systems and Software Program-Humanities and Society (WASP-Hs), funded by the Marianne and Marcus Wallenberg Foundation and the Marcus and Amalia Wallenberg Foundation (grant number: MMW 2018.0116). 